\title{
Improvement of defective cystic fibrosis airway epithelial wound repair after CFTR
}

\section{rescue}

\begin{abstract}
Nguyen Thu Ngan Trinh*,\#, Olivier Bardou*,, Anik Privé*, Emilie Maillé*, Damien Adam ", Sarah Lingée ", Pasquale Ferraro*,+, Martin-Yvon Desrosiers*, Christelle Coraux and Emmanuelle Brochiero*,\#
\end{abstract}

ABSTRACT: Airway damage and remodelling are important components of lung pathology progression in cystic fibrosis (CF). Although repair mechanisms are engaged to restore the epithelial integrity, these processes are obviously insufficient to maintain lung function in CF airways. Our aims were therefore to study how the basic cystic fibrosis transmembrane conductance regulator (CFTR) defect could impact epithelial wound healing and to determine if CFTR correction could improve it.

Wound-healing experiments, as well as cell migration and proliferation assays, were performed to study the early phases of epithelial repair in human CF and non-CF airway cells. CFTR function was evaluated using CFTR small interferring (si)RNA and inhibitor GlyH101 in non-CF cells, and conversely after CFTR rescue with the CFTR corrector VRT-325 in CF cells.

Wound-healing experiments first showed that airway cells from CF patients repaired slower than non-CF cells. CFTR inhibition or silencing in non-CF primary airway cells significantly inhibited wound closure. GlyH101 also decreased cell migration and proliferation. Interestingly, wild-type CFTR transduction in CF airway cell lines or CFTR correction with VRT-325 in CFBE$\Delta F 508$ and primary CF bronchial monolayers significantly improved wound healing.

Altogether our results demonstrated that functional CFTR plays a critical role in wound repair, and CFTR correction may represent a novel strategy to promote the airway repair processes in CF.

KEYWORDS: Bronchial, CFTR channel, CFTR corrector, damage, nasal, wound healing

n cystic fibrosis $(\mathrm{CF})$, mutations of the gene coding for cystic fibrosis transmembrane conductance regulator (CFTR) channels cause dysfunction of chloride $\left(\mathrm{Cl}^{-}\right)$secretion, resulting in unbalanced ion and fluid transport that reduces mucociliary clearance in the airways and favours bacterial colonisation and chronic inflammation [1]. The presence of bacterial virulence factors, proteases and inflammatory mediators are then responsible for airway damage and remodelling $[2,3]$. Severe bronchiectasis is the most commonly observed structural abnormality in CF airways. Ultrastructural modifications, including epithelial shedding [4-7], also occur, but their extent and severity are not well defined. The outcomes for the loss of epithelial integrity may be multiple. For example, epithelial shedding could play a role in bacterial colonisation by favouring Pseudomonas aeruginosa adherence [8-11], thus contributing to the progression of CF lung disease.

After injury, epithelial tissues initiate several repair processes, including cell spreading, migration, proliferation and re-differentiation, in an attempt to restore the normal architecture [12]. These processes are controlled by several growth factors, including epidermal growth factor (EGF), through EGF receptors (EGFR), which is a convergent pathway that produces motility and proliferative responses [3, 13-17]. We recently demonstrated that an autocrine EGF/EGFR loop and $\mathrm{K}^{+}$channel function are critical for epithelial repair [17]. Despite the establishment of epithelial repair mechanisms and the presence of high levels of growth factors in CF-patients' airways [3], airway epithelia are gradually damaged and
AFFILIATIONS

${ }^{*}$ Centre de recherche Centre hospitalier de l'Université de Montréal (CRCHUM),

"Département de médecine, Université de Montréal,

+Département de chirurgie, Université de Montréal, Montréal, Québec, Canada.

"INSERM UMRS 903, Université

Champagne Ardenne, Reims, France.

CORRESPONDENCE

E. Brochiero

CRCHUM

Hôtel-Dieu

3840

St-Urbain

Montréal

Québec

Canada H2W 1 T8

E-mail: emmanuelle.brochiero@

umontreal.ca

Received:

Dec 162011

Accepted after revision:

March 062012

First published online:

April 102012 
remodelled in CF patients. However, it is not yet clear whether the inability of CF airways to regenerate themselves is due to a basic repair defect of CF airway epithelia and/or to deleterious infectious and inflammatory mediators. Several lines of evidence indicate that the basic CFTR defect could impair epithelial repair and regeneration, even in the absence of infection. In fact, abnormal and delayed regeneration of CF airway epithelia were first observed in a nude mice xenograft model [18]. Subsequently, our in vitro data indicated that wound healing and cell migration in CF (CuFi-1) bronchial cell monolayers were slower than in non-CF (NuLi-1) cell monolayers [17]. In addition, it was shown that CFTR inhibition or knockdown in human airway epithelial cell line Calu-3 cells slowed down wound repair [19].

The first goal of our study was to test the hypothesis that the early processes engaged in airway epithelial repair are delayed in the primary monolayers from CF patients. To prove the involvement of CFTR channels, we evaluated the effect of CFTR downregulation on epithelial wound healing, as well as on cell migration and proliferation. Finally, we tested for the first time the ability of the CFTR corrector VRT-325 to improve CF airway epithelial wound healing.

\section{MATERIALS AND METHODS}

\section{Histological analysis of bronchial sections}

$\mathrm{CF}$ lung tissues were sourced from ten $\Delta \mathrm{F} 508 / \Delta \mathrm{F} 508 \mathrm{CF}$ transplanted patients (median age $21 \mathrm{yrs}$ at time of lung transplantation), chronically infected by $P$. aeruginosa, either alone or associated with Staphylococcus aureus, Candida albicans, Burkholderia cepacia or Aspergillus. Non-CF control bronchial tissues were obtained from donor organs not employed for transplantations. Tissue samples were fixed in Shandon Cryomatrix frozen embedding medium (Thermo Fisher Scientific, Kalamazoo, MI, USA) and snap frozen in liquid nitrogen before cutting into serial $5-\mu \mathrm{m}$ sections and staining with the Shandon Rapid chrome H\&E frozen section staining kit (Shandon, Thermo Fisher Scientific).

\section{Cell culture}

Several non-CF and CF cell lines have been used: NuLi-1 and CuFi-1 (homozygous $\Delta \mathrm{F} 508 / \Delta \mathrm{F} 508$ ), both generously provided by J. Zabner (University of Iowa, Iowa City, IA, USA) [20], IB3 $(\triangle \mathrm{F} 508 / \mathrm{W} 1282 \mathrm{X}, \mathrm{ATCC})$ and S9 (wild type (wt)-CFTR genetically repaired CF IB3 cells, ATCC); CFBE410 ${ }^{-}$transduced with wt-CFTR (CFBE-wt) or $\Delta$ F508-CFTR (CFBE- $\Delta$ F508) [21], kindly provided by J. Hanrahan (McGill University, Montreal, Quebec, Canada). Cell culture conditions are detailed in the online supplementary material.

Primary human bronchial cells were isolated from CF homozygous $\Delta \mathrm{F} 508 / \Delta \mathrm{F} 508$ lung transplants (median age $31 \mathrm{yrs}$, mean forced expiratory volume in $1 \mathrm{~s}$ (FEV1) $23.6 \pm 2.1 \%$ ) and non-CF donors, while primary human nasal cells were recovered after polypectomy procedures from non-CF and $\mathrm{CF}$ patients (with various genotypes, i.e. two homozygous $\Delta \mathrm{F} 508$ / $\Delta \mathrm{F} 508$, one $\Delta \mathrm{F} 508 / \mathrm{A} 555 \mathrm{E}$ and one $\mathrm{C} 621+1 \mathrm{G} \rightarrow \mathrm{T} / \mathrm{P}-\mathrm{L} 206 \mathrm{~W}$, median age 16 yrs, mean FEV1 of $81.6 \pm 14.2 \%$ ), according to ethically approved protocols. Cell isolation and culture conditions are provided in the online supplementary material.

\section{Wound-healing assay}

Airway epithelial cells were injured mechanically with a P10 pipette tip (six wounds per Petri dish) according to a highly reproducible technique $[16,17,22]$. This commonly employed "wound-healing assay" allows study of early mechanisms engaged after injury, i.e. cell migration and proliferation. A mark on the Petri dishes allowed us to photograph the wounds at exactly the same place at various times (at time 0 after injury and after $6 \mathrm{~h}$ and/or $24 \mathrm{~h}$ of wound closure). The rate of wound closure, presented in $\mu \mathrm{m}^{2} \cdot \mathrm{h}^{-1}$, was calculated with ImageJ software (National Institutes of Health, Bethesda, MD, USA) from the wound area measured after repair compared with the initial wound area.

\section{Time-lapse experiments}

NuLi-1 and CuFi-1 cell migratory rates $\left(\mu \mathrm{m} \cdot \mathrm{h}^{-1}\right)$ were evaluated by single-cell tracking at the wound edge in videomicroscopy experiments, over a 60 -min period of repair $(\times 10$ enlargement). In primary nasal cells, time-lapse experiments were performed over a 6-h period on subconfluent monolayers $(\times 20$ enlargement). The migration rate and cell trajectories were analysed by AxioVision software (Carl Zeiss, Jena, Germany).

\section{Cell proliferation assays}

Cell growth during wound-healing assays was evaluated by counting NuLi-1 and CuFi-1 cell numbers after separation using trypsin-EDTA in confluent monolayers before injury, at time 0 after injury and after $24 \mathrm{~h}$ of wound healing [22]. Cell viability was verified by trypan-blue exclusion assay. Cell proliferation was also estimated by $\left[{ }^{3} \mathrm{H}\right]$ thymidine incorporation $\left(0.5 \mu \mathrm{Ci} \cdot \mathrm{mL}^{-1}\right.$; MP Biochemical, Irvine, CA, USA) over 6-h and 18 -h periods in subconfluent $\mathrm{NuLi}-1$ and $\mathrm{CuFi}-1$ cultures, as previously described [17].

Proliferation of primary nasal cells during wound healing was assessed by Ki-67 staining. Briefly, confluent nasal cell monolayers, cultured on Labtek chamber slides (Thermo Fischer Scientific, Rochester, NY, USA), were fixed in methanol at time 0 after injury and after $6 \mathrm{~h}$ and $18 \mathrm{~h}$ of repair, before staining with anti-Ki67 antibody (Dako Denmark, Glostrup, Sweden), then with Alexa fluor 488 goat anti-mouse secondary antibody (Invitrogen, Carlsbad, CA, USA), and finally counterstaining with 4',6-diamidino-6-phenylindole (DAPI; SigmaAldrich Company Ltd, Gillingham, UK). The results are presented as a percentage of Ki-67 positive proliferating cells compared with total cells.

\section{Small interferring (si)RNA transfections}

Cell suspensions of non-CF primary human nasal epithelial cells were transfected for $72 \mathrm{~h}$ with a combination of Lipofectamine $^{\mathrm{TM}}$ RNAiMAX (Invitrogen) and Universal negative control or CFTR siRNA (Sigma-Aldrich) and plated on Petri dishes coated with Purecol (Advanced Biomatrix, San Diego, CA, USA).

\section{Statistics}

The data are presented as mean $\pm \mathrm{SE}$ with the number of repeated experiments and number of specimens indicated in the figure legends. Groups were compared by paired or unpaired $t$-test (as indicated) with Statview software (SAS Institute, Cary, NC, USA). Probability of $\mathrm{p}<0.05$ was considered to be significant. 

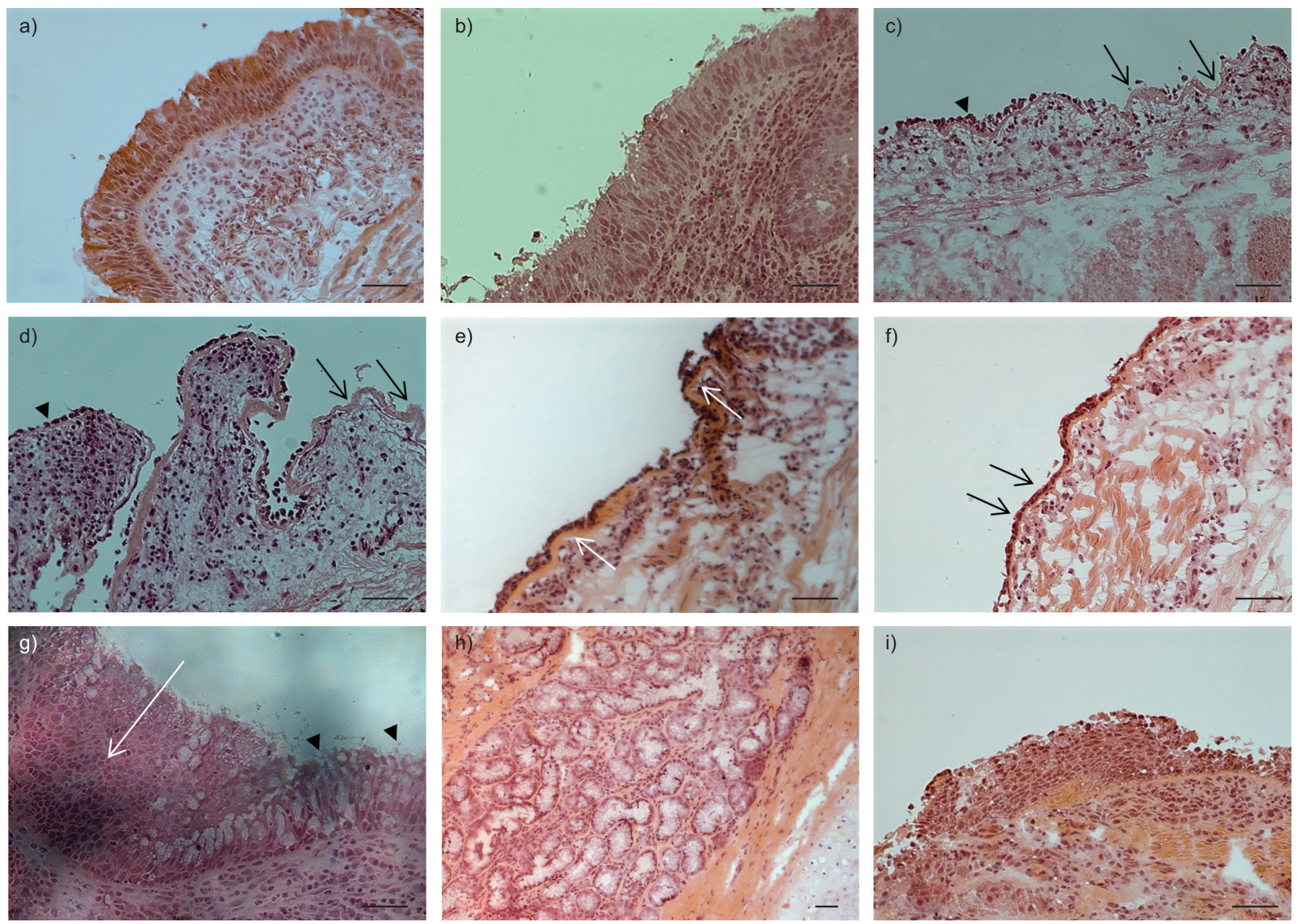

FIGURE 1. Airway epithelial alteration and remodelling in cystic fibrosis (CF) patients. Microscopic histological observation of haematoxylin and eosin stained non-CF (a) and CF (c-i) lobar and segmental bronchial sections. b) shows an intact pseudostratified area with basal, ciliated and goblet cells in CF bronchial epithelium that is similar to that observed in the non-CF airway epithelium (a). c) Lobar and d) segmental sections, respectively, show epithelial desquamation (arrows) with complete basement membrane denudation and areas where some basal cells are still attached to the basement membrane (arrowheads). e) White arrows show basement membrane thickening f) Apparent epithelial repair with typically flattened cells covering the basement membrane (arrows) is observed. g) Basal and goblet cell hyperplasia is generally evident (indicated by white arrow and black arrowheads, respectively), as are gland hyperplasia (h) and squamous metaplasia (i). Magnifications are $\times 10$ (a-g, i) and $\times 20$ ( $h$ ). a-i) Scale bar $=50 \mu \mathrm{m}$.

\section{RESULTS}

\section{Histological modifications of the CF airway epithelia}

Histological alterations and remodelling of CF airways were analysed in bronchial sections of lung tissues collected from CF patients. In seven out of 10 patients, we detected focal areas with normal architecture of the pseudo-stratified epithelium (fig. 1b), similar to non-CF samples (fig. 1a). However, all 10 patients presented large areas of epithelial shedding at the lobar (fig. 1c) and segmental (fig. 1d) bronchial levels. In two out of $10 \mathrm{CF}$ patients, partially repaired epithelial areas, with flattened epithelial cells covering the basement membrane, were observed (fig. 1f). In addition to epithelial injury, extended epithelial remodelling was noted with basement membrane thickening (fig. 1e), basal (five out of 10 patients) and secretory (seven out of 10 patients) cell hyperplasia (fig. 1g), gland hyperplasia and hypertrophy (10 out of 10 patients; fig. 1h) as well as squamous metaplasia (seven out of 10 patients; fig. 1 i).

\section{Defective repair in human CF cell lines and primary cells}

A well-established wound-healing assay with mechanical injury [16, 17, 22-24] was used to study the early processes of airway repair, especially cell migration and proliferation (fig. 2). We first observed that the wound-closure rate in nonCF NuLi-1 cell monolayers was significantly higher than in CuFi-1 cell monolayers (fig. 2a). To further investigate the delay in CF wound repair, we also evaluated their migratory and proliferative capacity after injury. The cell migration, assessed by tracking single, randomly selected cells at the wound edge in videomicroscopy experiments, showed that the mean migration rate of NuLi-1 cells was faster than that of CuFi-1 cells (fig. 2b). Cell growth was then compared in NuLi-1 and CuFi-1 repairing monolayers. After wounding, the 
a)
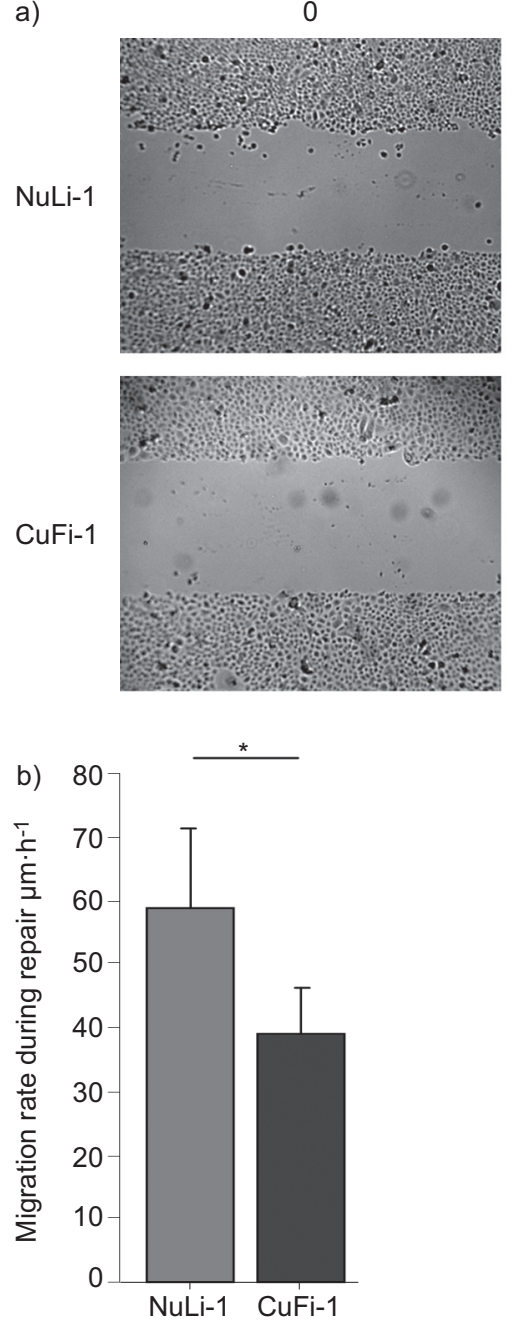

Time h
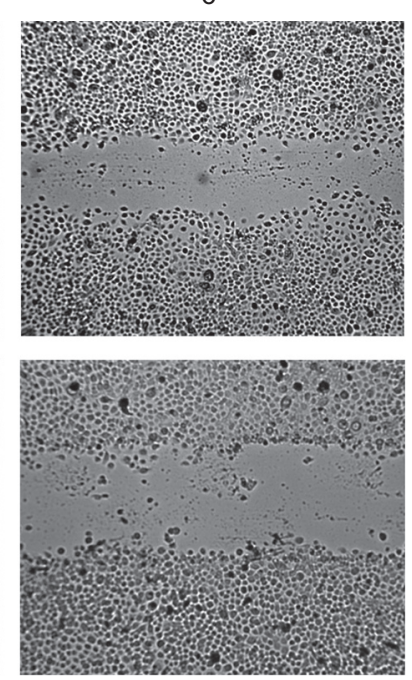

c)

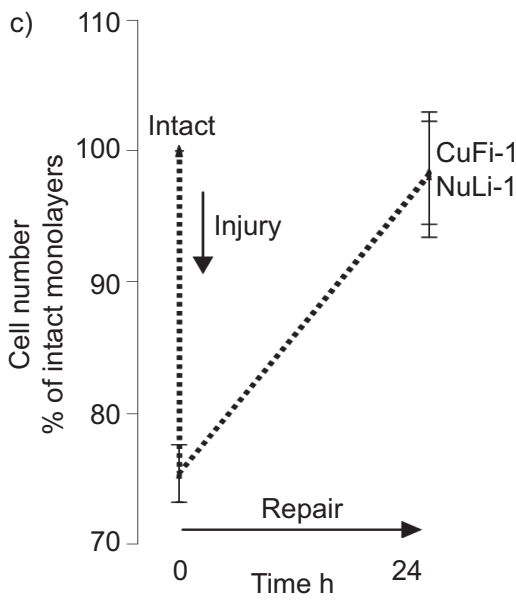

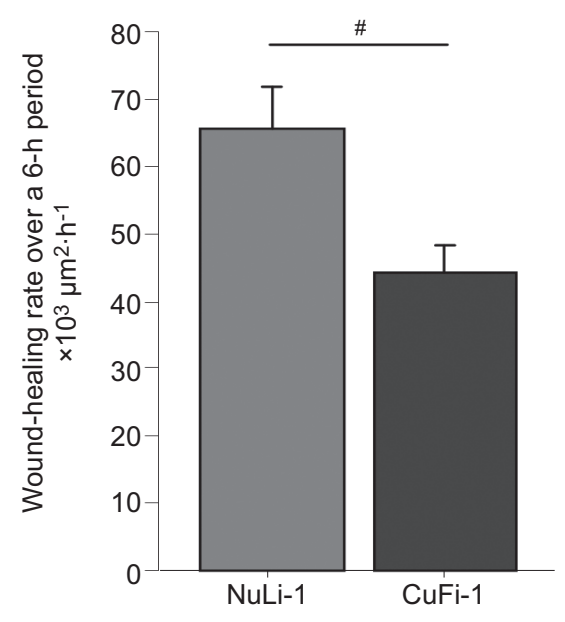

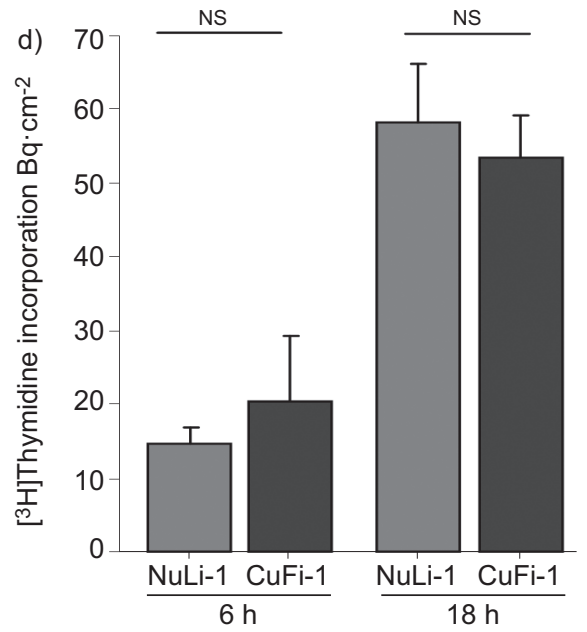

FIGURE 2. Delayed wound closure and cell migration in cystic fibrosis (CF) bronchial cell line (CuFi-1). a) Bronchial NuLi-1 and CuFi-1 cells were mechanically injured and wound healing was followed over a 6 -h period $(n=23, *: p<0.0001)$. Wound-closure rates and representative photographs at $0 \mathrm{~h}$ and $6 \mathrm{~h}$ are presented. b) Cell migration rates during repair of NuLi-1 and CuFi-1 cells (30 cells at the wound edge per experiment, $n=7 ;$ *: $p<0.05$ ) were calculated from live time-lapse videomicroscopy experiments over a 1-h period after injury to focus on cell migration and to avoid any significant cell proliferation. c) Cell growth during repair was estimated from the number of NuLi-1 and CuFi-1 cells counted before injury (intact), at time 0 after wounding, and finally after $24 \mathrm{~h}$ of repair ( $\mathrm{n}=8$; nonsignificant (NS)). $\mathrm{d}$ ) Cell proliferation of subconfluent NuLi-1 and CuFi-1 cell monolayers were estimated by $\left[{ }^{3} \mathrm{H}\right]$ thymidine incorporation $\left(\mathrm{Bq} \cdot \mathrm{cm}^{-2}\right)$ over shorter periods of time $(6 \mathrm{~h}$ and $18 \mathrm{~h}, \mathrm{n}=9$; NS).

mean total number of cells was reduced by $25 \%$ compared with the intact monolayer. After $24 \mathrm{~h}$, the NuLi-1 and CuFi-1 cell counts returned to the initial level measured before injury, indicating an active cell growth during wound healing in both cell lines (fig. 2c). Similarly, $\left[{ }^{3} \mathrm{H}\right]$ thymidine incorporation over shorter time periods $(6 \mathrm{~h}$ and $18 \mathrm{~h})$, in subconfluent, intact cultures indicated similar cell proliferation in both cell types (fig. 2d). Therefore, the delay in CuFi-1 wound closure most likely seems to be due to a difference in migratory rather than proliferative capacity.

Because the delay in CuFi-1 wound healing could be attributed to a genotypic difference between NuLi-1 and CuFi-1 cells, we decided to compare primary airway epithelial cells isolated from non-CF and CF patients. The wound-closure rate of CF human bronchial cell monolayers was $63 \%$ slower than that of
non-CF bronchial monolayers (fig. $3 \mathrm{a}$ and b). However, because these $\mathrm{CF}$ specimens were collected from transplants with late-stage lung disease (mean FEV1 of 23\%), we decided to examine a possible wound-healing delay in nasal primary airway cells from younger CF patients with better clinical conditions (mean FEV1 of $82 \%$ ). We found that the wound closure in CF human nasal monolayers was delayed when compared with non-CF (53\% slower wound-healing rate, fig. $3 \mathrm{c}$ and d). Taken together, our results demonstrated that CF airway epithelia exhibit a defect in wound repair after injury.

\section{Role of CFTR channels in wound healing}

To determine if the absence of functional CFTR could affect the wound-healing capacity and could be responsible for the defective repair, human non-CF primary nasal cells were 
a)
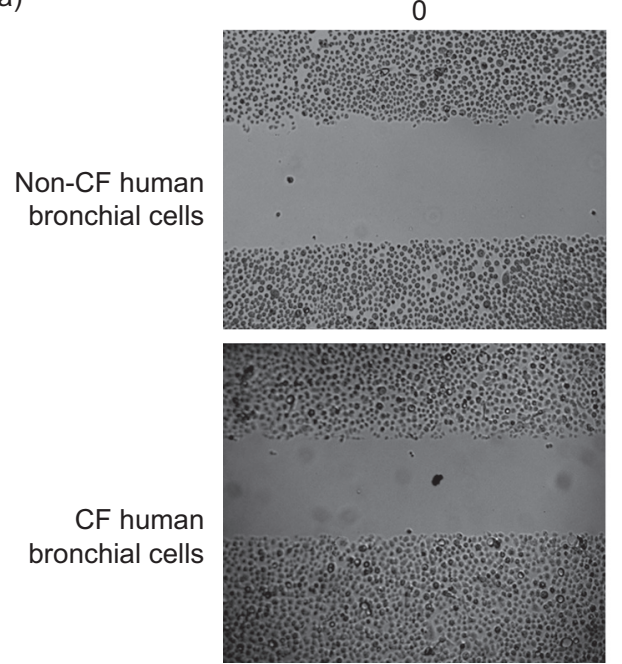

c)

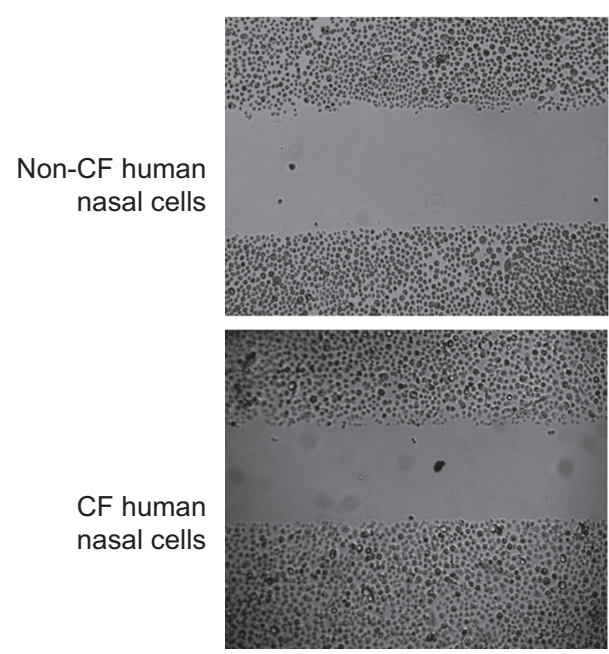

Time $\mathrm{h}$
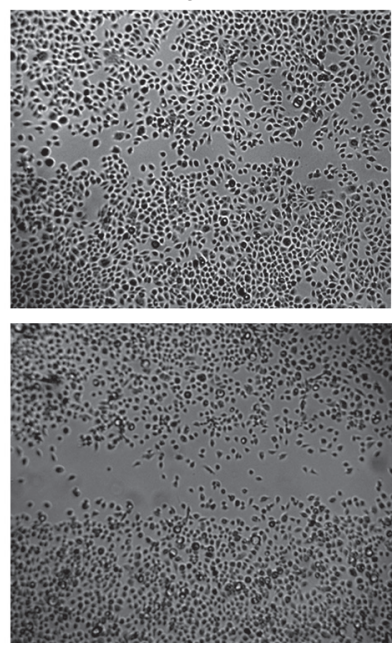

Time h
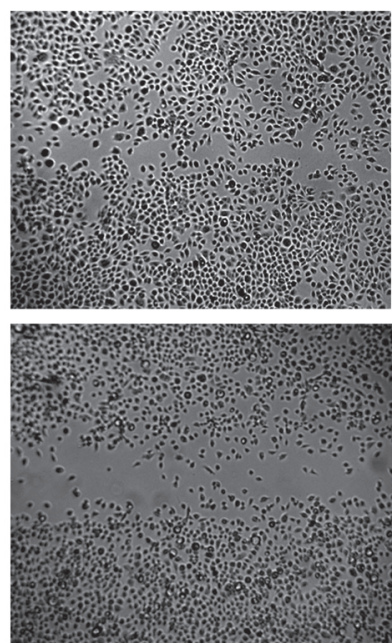
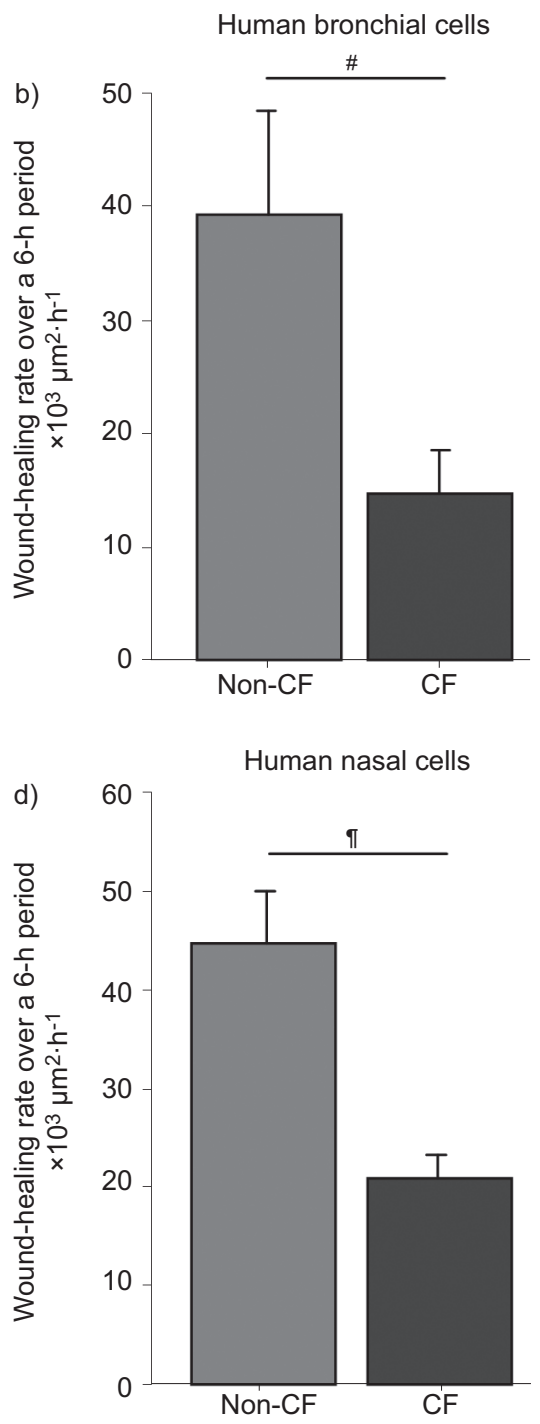

FIGURE 3. Delayed wound closure in human cystic fibrosis (CF) primary airway cell monolayers. a, b) Monolayers of primary human bronchial cells, from non-CF donors $(n=7)$ and $C F$ recipient patients $(\Delta F 508 / \Delta F 508, n=8 ; *: p<0.03)$ isolated after lung transplantation and $c, d)$ primary human nasal cells from non-CF and $C F$ patients $(n=4 ; "$ : $\mathrm{p}<0.006)$ were wounded. Their wound-healing rates were compared after $6 \mathrm{~h}(\mathrm{~b}, \mathrm{~d})$. Representative photographs at $0 \mathrm{~h}$ and $6 \mathrm{~h}$ after injury are presented in a) and $\mathrm{c}$ ).

transfected with either universal negative control or CFTR siRNA. The efficiency of CFTR siRNA to downregulate CFTR mRNA and protein expression was verified first (fig. S1). We found that partial CFTR silencing elicited a significant decrease in wound healing (fig. 4a and b) in all nine tested patients (mean closure rates of 79,528 $\pm 12,463$ and $55,649 \pm 10,176 \mu \mathrm{m}^{2} \cdot \mathrm{h}^{-1}$ in control and CFTR siRNA conditions, respectively; $\mathrm{p}<0.002$ ). To determine if the $\mathrm{Cl}^{-}$conductance through CFTR channels is involved in this phenomenon, the impact of the CFTR inhibitor GlyH101was tested. As depicted in fig. 4c and d, GlyH101 reduced the woundhealing rates of the nasal cell monolayers by $47 \%$.

The role of CFTR in cell migration dynamics was assessed by single-cell tracking of subconfluent non-CF nasal cells in videomicroscopy. As observed in fig. $5 \mathrm{a}$, CFTR inhibition reduced cell migration rates and affected cell trajectories. The effect of CFTR inhibition on cell proliferation, estimated by Ki-67 staining of nasal cells during wound healing, was also determined. CFTR inhibition elicited a slight, nonsignificant decrease in Ki-67 positive cells at $6 \mathrm{~h}$; however, it reduced by one-third $(\mathrm{p}<0.03)$ the number of proliferating cells at $18 \mathrm{~h}$ of wound healing as reported in figures $5 \mathrm{c}$ and $\mathrm{d}$. Altogether, these results indicate that functional CFTR channels are crucial for airway wound healing, as well as cell migration and proliferation processes.

\section{Impact of CFTR correction on airway wound healing}

Since the observed delay in CF wound healing may be due, at least in part, to CFTR dysfunction, a possible beneficial impact of CFTR correction was evaluated. The wound-healing rates of the CF cell line IB3 and the wt-CFTR corrected IB3 (S9) cell line were compared: S9 cell monolayers exhibited a 30\% increase in the wound-healing rate compared with IB3 (fig. 6a) Similarly, we noted $\sim 1.3$-fold improvement in the wound-healing capacity of CFBE41o cells over-expressing wt-CFTR relative to cells expressing $\Delta$ F508-CFTR (fig. $6 \mathrm{~b}$ ). 
a)

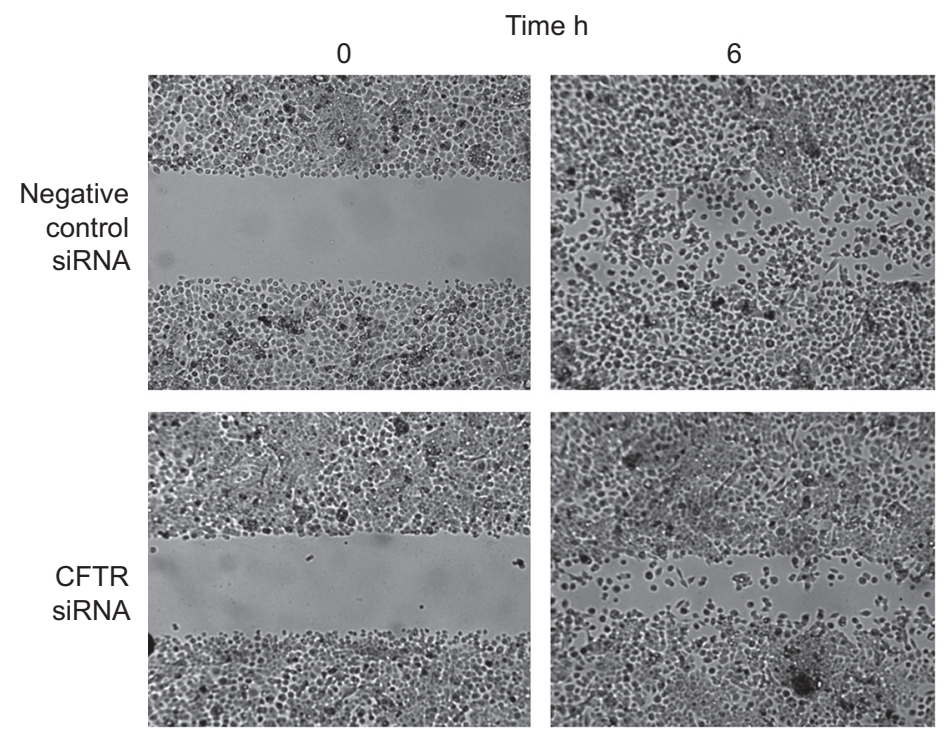

c)

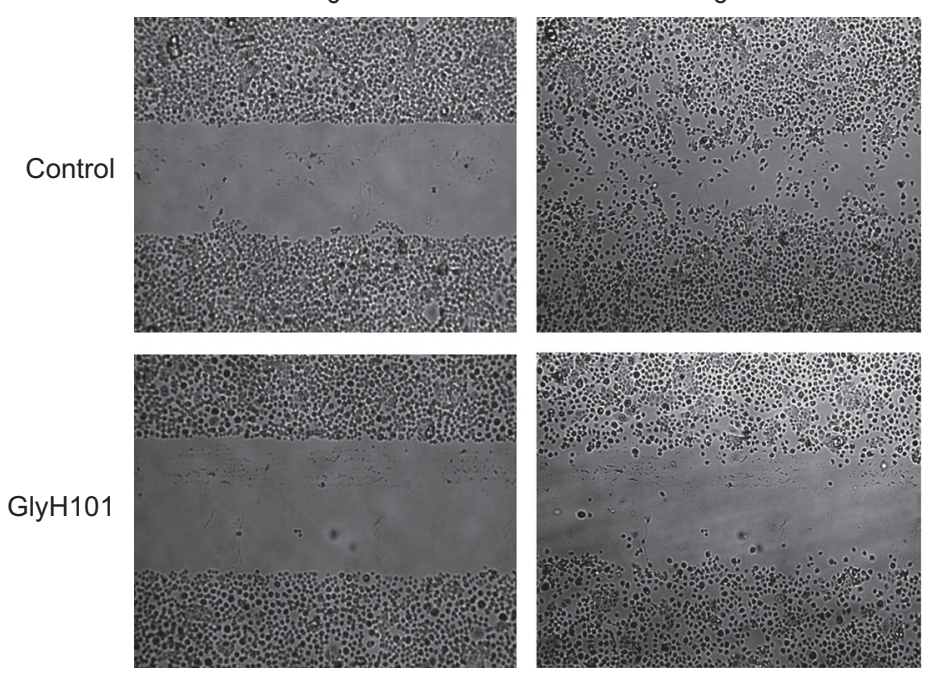

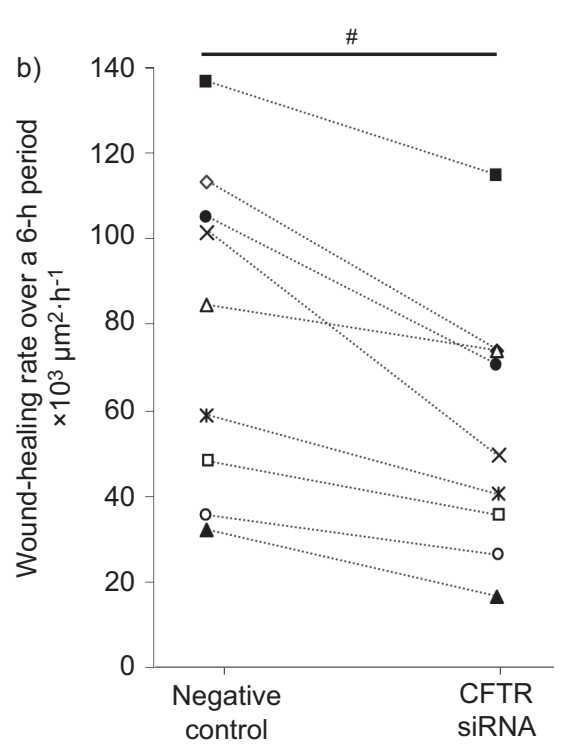

d) $\quad 60\left[\begin{array}{l}\pi \\ \hline\end{array}\right.$

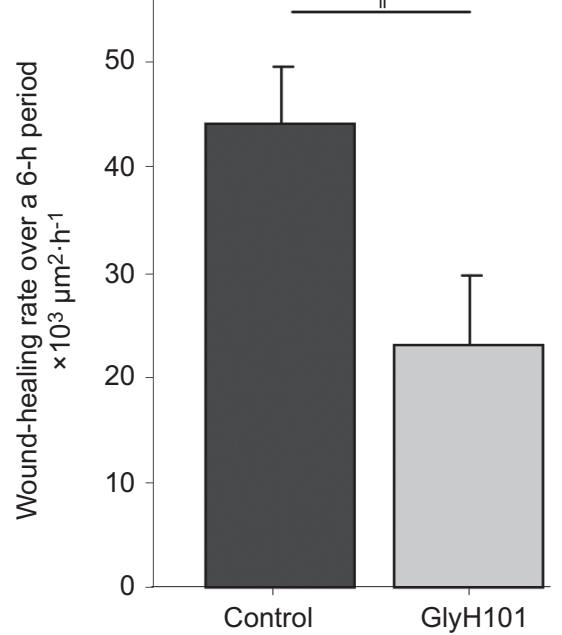

FIGURE 4. Decreased wound healing after cystic fibrosis transmembrane conductance regulator (CFTR) silencing and inhibition in primary airway cell monolayers. a, b) Primary airway nasal non-cystic fibrosis (CF) cells were transfected with universal negative control siRNA (100 nM) or CFTR siRNA (100 nM). Wound-healing rates were measured at $6 \mathrm{~h}$ after injury in both conditions (negative control or CFTR siRNA; $\left.{ }^{*}: \mathrm{p}<0.02\right)$ for nine different patients (each symbol represents a different patient). c, d) Wound-healing rate of primary non-CF nasal cell monolayers was measured at $6 \mathrm{~h}$ after injury in the presence or absence (control) of the CFTR inhibitor GlyH101 (20 $\mu \mathrm{M}, 1$ - $\mathrm{h}$ pre-treatment, $n=6 ; ": p<0.03)$. Representative photographs at $0 \mathrm{~h}$ and $6 \mathrm{~h}$ are presented in a) and c).

New pharmacological tools, including the corrector VRT-325 have been shown to rescue misprocessed CFTR, particularly $\Delta$ F508-CFTR [25-28]. We first verified that VRT-325 was able to partially rescue CFTR protein and to recover channel activity in CFBE- $\triangle$ F508 cells (fig. S3). VRT-325 also significantly enhanced the wound-repair rates of CFBE- $\Delta$ F508 cell monolayers (fig. 7a) reaching a level closer to that of CFBE-wt. Interestingly, CFTR rescue with VRT-325 also improved the wound-healing rates in primary bronchial cell monolayers from all four tested CF lung transplants (mean 1.8-fold increase; fig. 7b).

\section{DISCUSSION}

Our study first revealed extended epithelial damage and remodelling in bronchial sections taken from CF patients.
Despite the establishment of epithelial repair, in an attempt to restore the epithelial barrier, these mechanisms seem obviously insufficient to maintain a normal epithelial architecture. In fact, our results demonstrate that wound healing is delayed in $\mathrm{CF}$ epithelia compared with non-CF controls. In addition, our data suggest that functional CFTR channels are crucial for wound healing, as well as cell migration and proliferation processes. Interestingly, CFTR correction improves the wound-repair rates of CF cell monolayers. Taken together, our findings establish that CFTR is important in the early airway epithelial repair processes and highlights a new, unsuspected function of CFTR correctors that could improve the repair of damaged CF airway epithelia. 


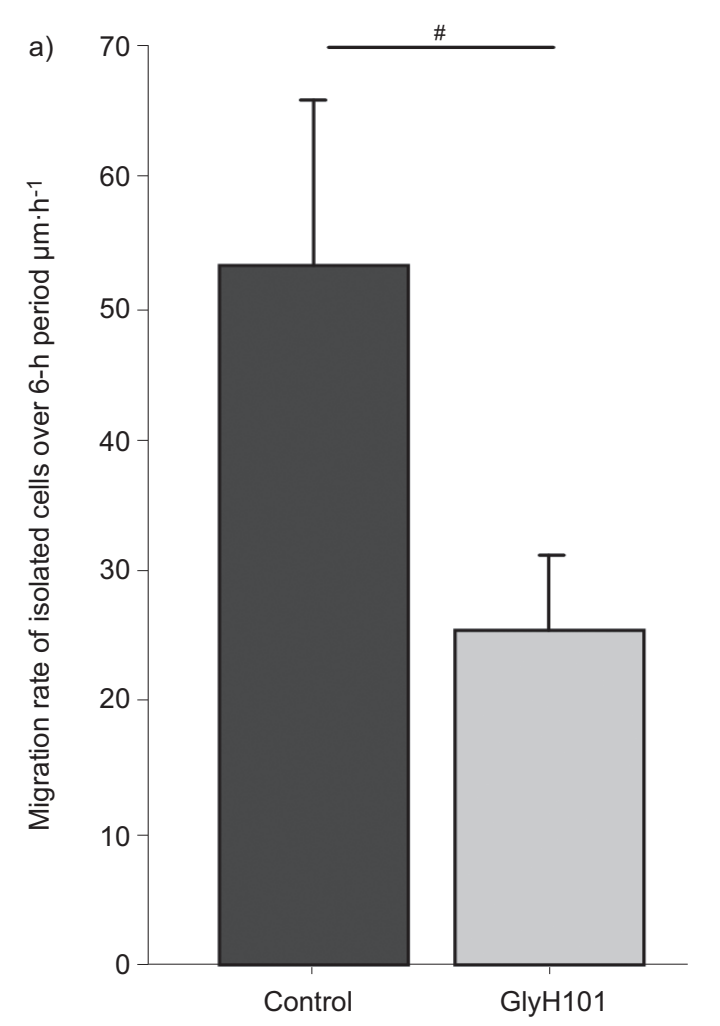

b)

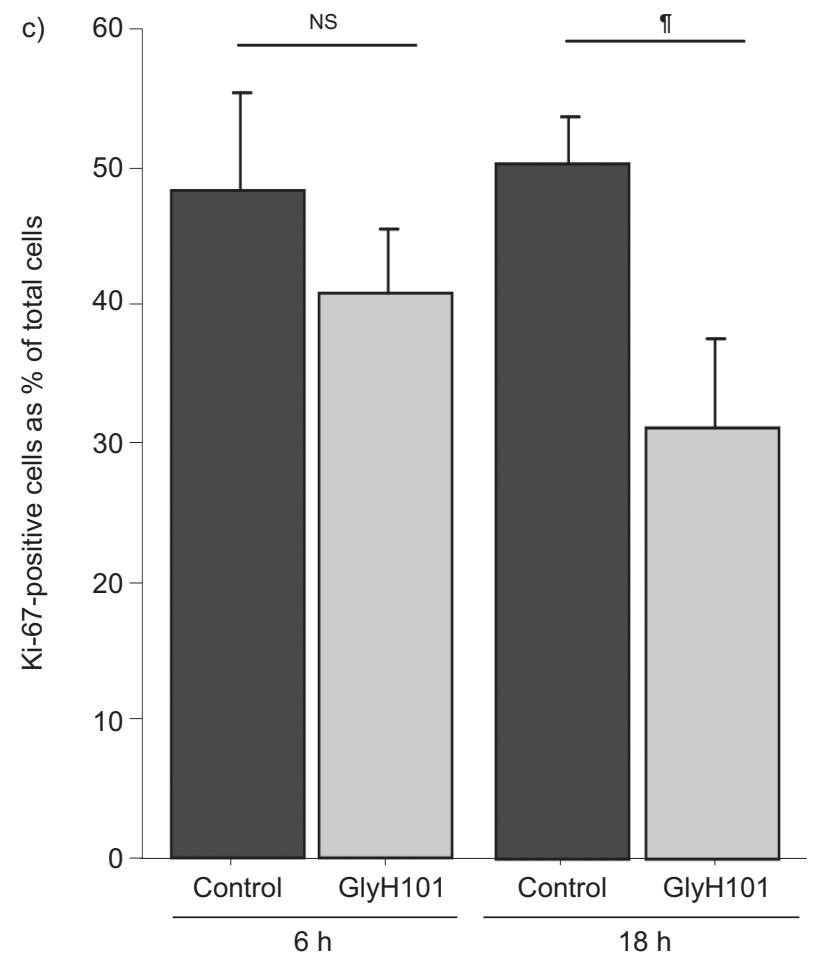

d)
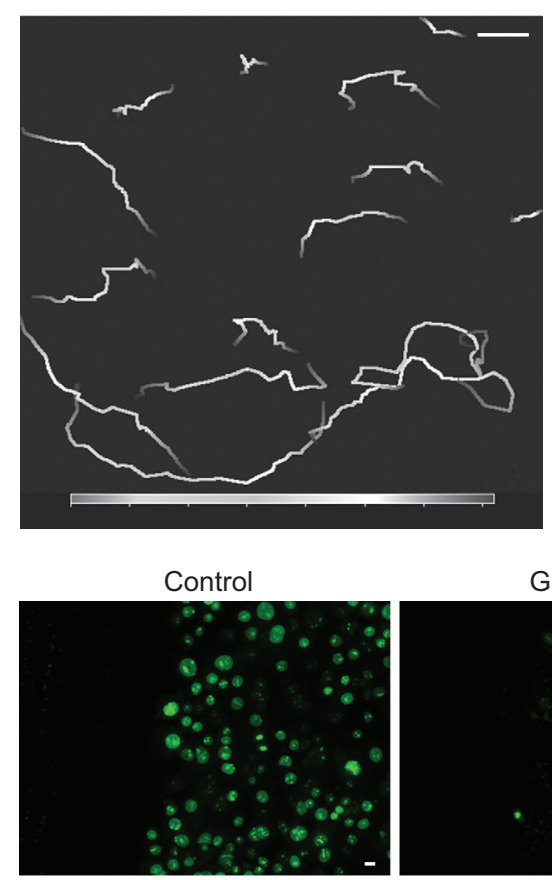

Ki-67
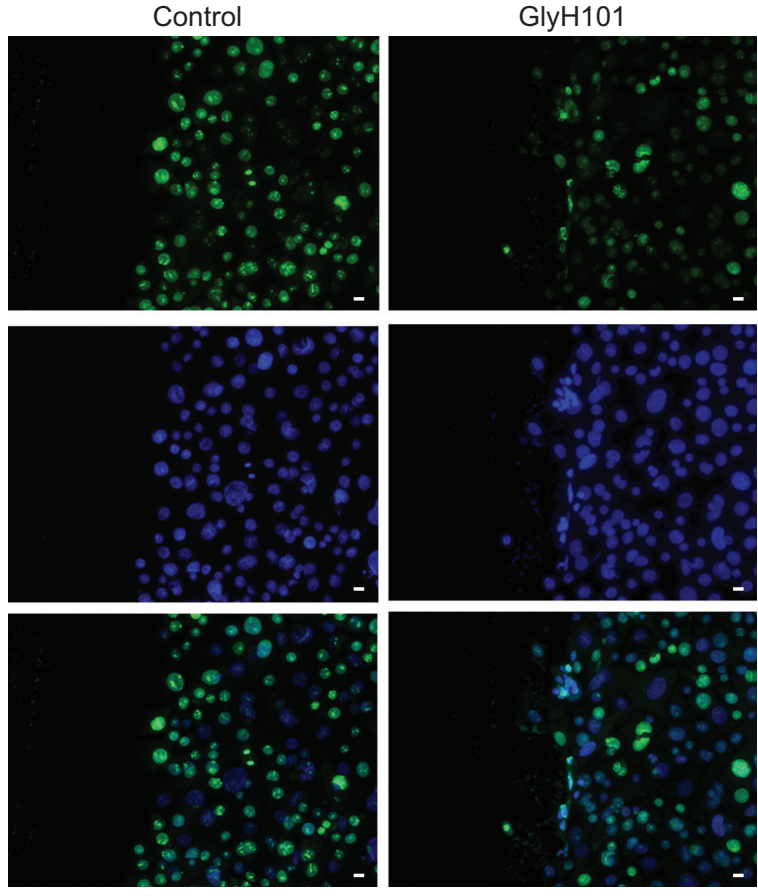

FIGURE 5. Decreased cell migration and proliferation after cystic fibrosis transmembrane conductance regulator (CFTR) inhibition in primary airway cell monolayers. a) Mean cell migration rate and trajectories (see representative tracks in b) were evaluated by single-cell tracking of subconfluent non-cystic fibrosis (CF) primary nasal cells (15 cells per condition) in control conditions or in the presence of GlyH101 (10 $\mu \mathrm{M}, 1$-h pre-treatment, $\mathrm{n}=4$; $\left.{ }^{*}: \mathrm{p}<0.04\right)$. Scale bar $=50 \mu \mathrm{m}$. c) Cell proliferation during wound repair of primary non-CF nasal cell monolayers was evaluated by Ki-67 immunostaining. Quantification of the number of Ki-67 positive cells (green cells), expressed as percentage of total cell number (4',6-diamidino-6-phenylindole (DAPI)-positive blue cells), at 6-h and 18-h of repair reported under control and GlyH101 conditions (20 $\mu \mathrm{M}$, 1-h pre-treatment, $n=3 ;{ }^{\prime}: p<0.03$ ). d) Representative photographs ( $\times 20$ enlargement) of Ki-67 and DAPI staining, as well as merged images, under control conditions and in the presence of GlyH101 (at $18 \mathrm{~h}$ of repair). Scale bar $=10 \mu \mathrm{m}$. See figure S2 for negative control and $\times 10$ enlargement representative photographs. 
a)

IB3
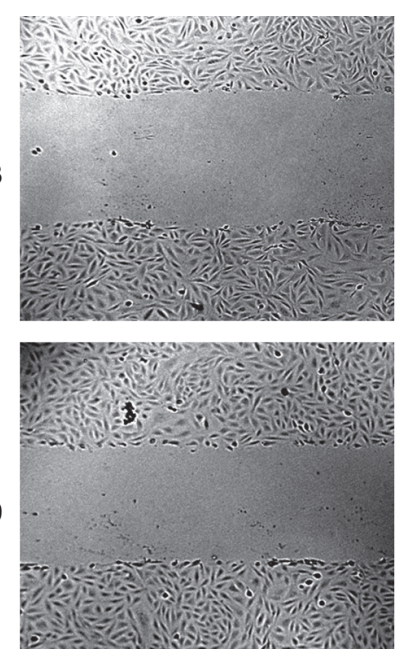

0
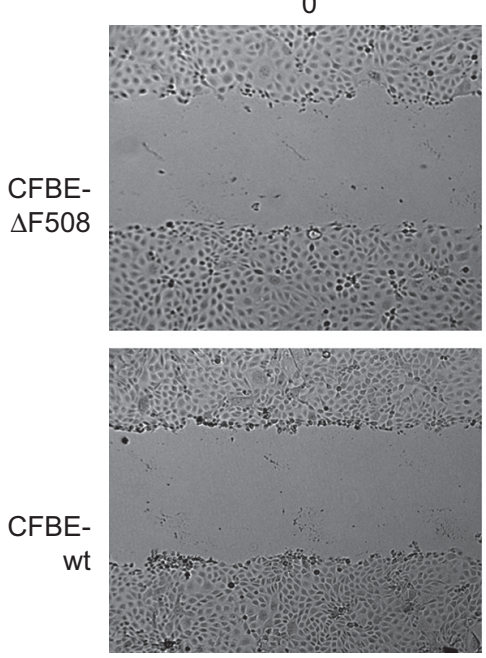

Time h
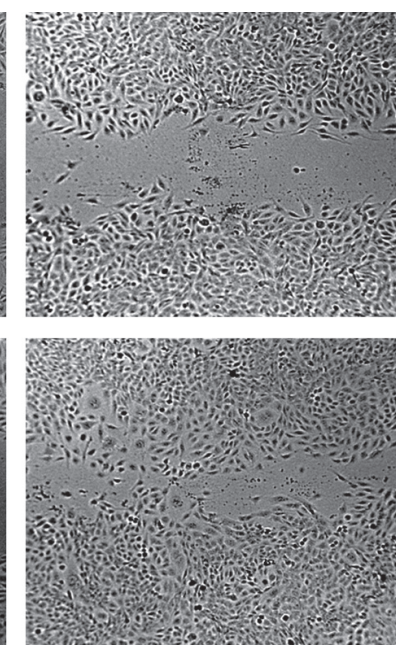

Time $\mathrm{h}$
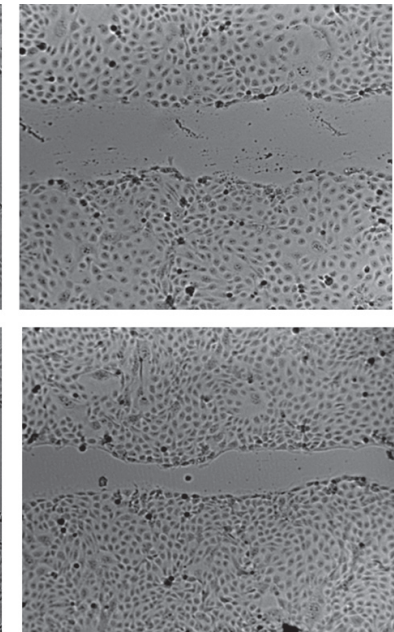

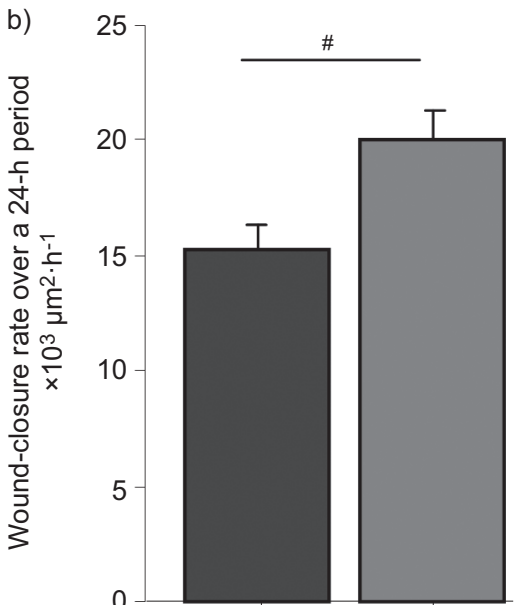

IB3

S9

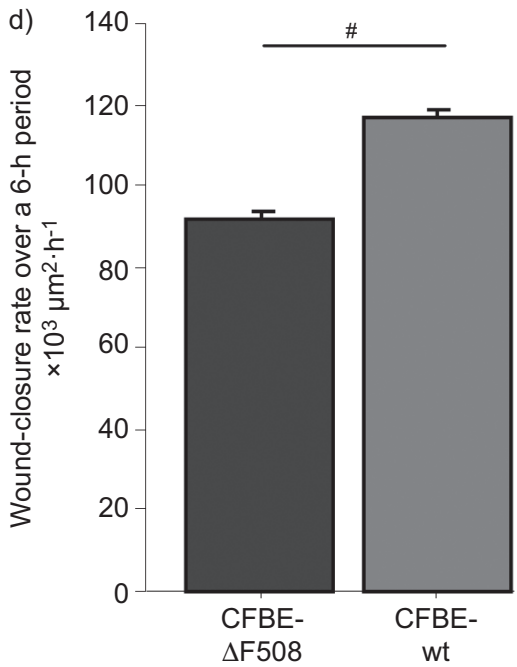

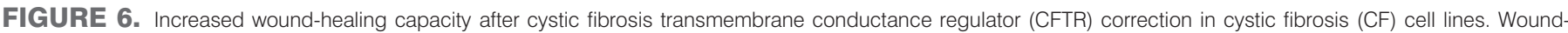
closure rates of b) the CF cell line IB3 and the IB3 cell line corrected with wild-type (wt)-CFTR (S9 cell line) ( $\mathrm{n}=20$; $\left.{ }^{*}: \mathrm{p}<0.0001\right)$ and d) CFBE410- cells overexpressing $\Delta$ F508-

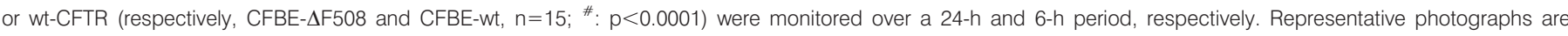
presented in a) and c).

\section{Severity of epithelial injury and remodelling of CF airways}

Our histological analysis of CF lung sections revealed significant tissue remodelling, including secretory and basal cell hyperplasia, gland hypertrophy, as well as squamous metaplasia, in most patients, in agreement with previous reports $[3,4,7,29,30]$. Our analysis also detected areas of extended and severe epithelial shedding in 100\% of analysed CF patients. In $70 \%$ of patients, some areas retained a normal architecture, indicating that the severity of airway epithelial injury may be variable among areas and patients, even at the time of transplantation $[4,31]$. In this study we focused on bronchial sections; however, previous papers also reported marked epithelial alterations in nasal upper airways [6, 32], trachea [6] and bronchioles [4, 5] as well as in alveoli [4, 33]. Previous ultrastructural analysis also revealed disorganisation of epithelial tight junctional complexes and dysmorphology of cilia $[6,34]$.
Although bronchiectasis is commonly correlated with loss of lung function in $\mathrm{CF}$ patients, other parameters, such as bronchial wall thickening, atelectasis-consolidation [35] and epithelial damage [34], are also associated with decline in FEV1 and poor clinical lung conditions. The lost epithelial integrity may favour bacterial adherence and colonisation [8-11]. Moreover, the loss of ciliated cells could worsen the already dysfunctional mucociliary clearance, while a decrease in the number of Clara and ATII cells may further affect the defence against pathogens [4-6, 30,34]. These phenomena are thus creating a vicious circle of infections, inflammation and injury exacerbation, central to the progression of CF lung disease.

\section{Defective wound healing in CF airway monolayers}

In two patients, we detected areas of partial bronchial epithelial repair. Alveolar epithelial regeneration in CF has also been reported elsewhere $[5,36]$. Despite such evidence of 

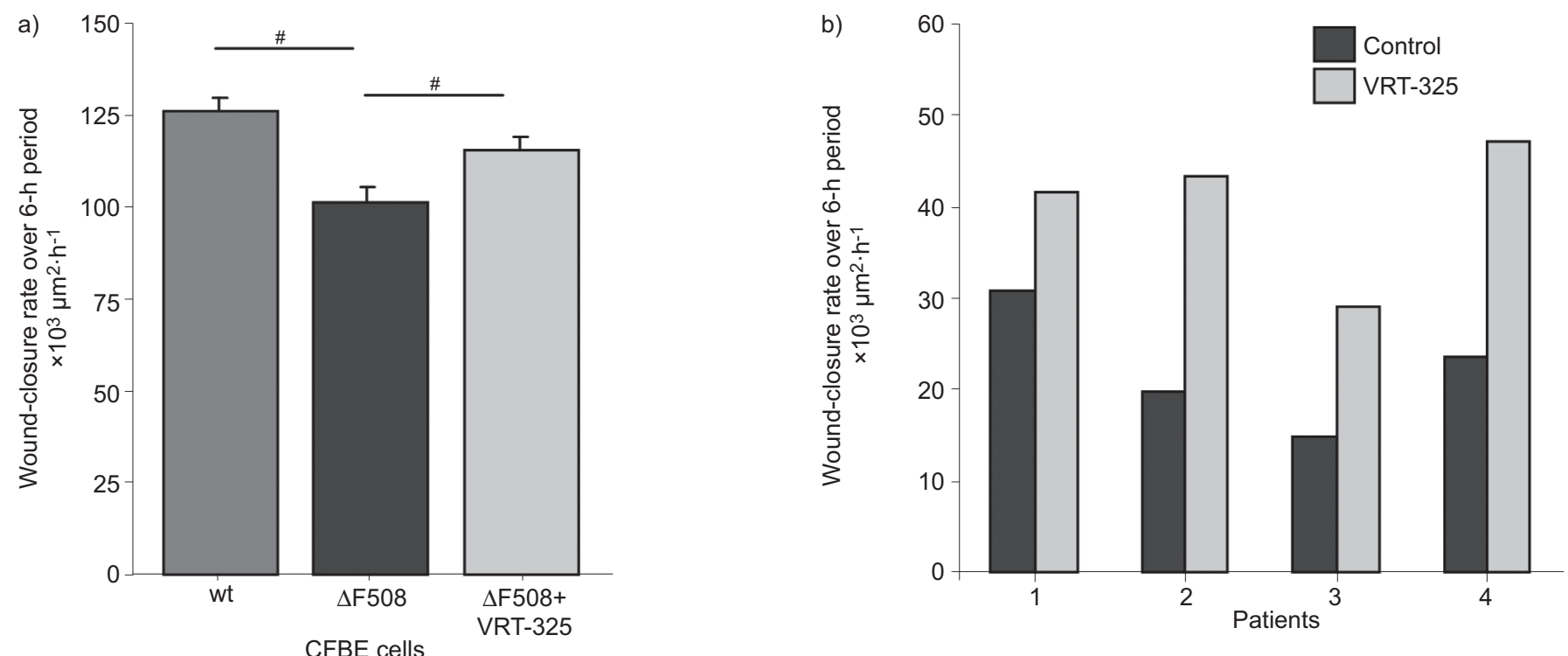

FIGURE 7. Cystic fibrosis transmembrane conductance regulator (CFTR) correction with VRT-325 enhanced the wound-healing capacity of cystic fibrosis (CF) cell monolayers. a) CFBE- $\Delta$ F508 and CFBE-wild type (wt) cells ( $n=9 ;: p<0.002)$, as well as b) primary human CF bronchial cell monolayers $(n=4 ; p<0.02)$ were wounded and wound-closure rates were monitored over a 6-h period, either under control conditions or after CFTR rescue with treatment with VRT-325 (5 $\mu \mathrm{M})$, for 18-24 h before injury.

epithelial repair, progressive lung tissue destruction and deterioration of clinical conditions $[7,34]$ was reported in $\mathrm{CF}$ patients. In fact, our in vitro data indicated that the woundhealing process is less effective in CF than in non-CF airways. Indeed, we found that wound-closure rates in the CF cell lines $\mathrm{CuFi}-1, \mathrm{IB} 3$ and CFBE- $\Delta$ F508 were slower than in their related non-CF cell lines. More importantly, this delay was confirmed in primary cells from CF patients, suggesting a basic defect in $\mathrm{CF}$ wound healing, in a pathogen-free model. Moreover, it should be noted that the repair delay was observed in bronchial monolayers (a $63 \%$ difference compared with non$\mathrm{CF}$ ) from late-stage patients, with a long background of infections and/or exacerbation, as well as in nasal epithelial cell monolayers (53\% decrease) from younger patients with early-stage disease. In agreement with our data, abnormal and delayed regeneration of human CF airway epithelium was also noted previously in a murine xenograft model that was free of infection [18]. Furthermore, in the airways of CF patients, the presence of virulence factors, proteases, oxidants and inflammatory mediators may further delay and consequently increase epithelial damage and remodelling.

\section{Control of wound-healing processes by CFTR}

CFTR inhibition or silencing elicited a decrease in wound healing of non-CF airway cell monolayers, demonstrating the role of CFTR in that phenomenon. The effect of channel inhibition by GlyH101 on wound closure, and cell migration and proliferation suggested that the CFTR conductance (and not only the protein per se) could be involved. However, the mechanisms whereby CFTR could control these repair mechanisms are not yet clearly defined. In fact, $\mathrm{K}^{+}$and $\mathrm{Cl}^{-}$ channels are important regulators of cell volume and intracellular calcium signalling required for proliferation and migration [37, 38]. Volume-dependent $\mathrm{ClC}$ chloride channels, for example, are involved in the proliferation and migration of several cell types [39-41]. Moreover, $\mathrm{Cl}^{-}$influx through $\mathrm{Cl}^{-}$ channels creates local swelling that is implicated in the formation of microglial lamellipodia [42]. Similarly, SCHILLER et al. [19] recently reported that CFTR downregulation in airway Calu-3 cells reduced wound healing and lamellipodia protrusion. In addition, CFTR activity has been shown to establish oriented electrical fields required to guide cell migration and promote wound healing in rhesus monkey trachea [43]. In our study, it should be noted that GlyH101 and CFTR siRNA did not completely depress wound repair. The partial effect of CFTR siRNA on wound healing could be explained by the partial silencing of CFTR expression. However, channels other than CFTR, especially $\mathrm{K}^{+}$channels, participate in the control of airway epithelial repair, as we recently demonstrated [16, 17]. A cooperative role of $\mathrm{Cl}^{-}$ channels, favouring cell protrusion, and of $\mathrm{K}^{+}$channels, necessary for retraction of cell bodies during cell migration, has been postulated [37].

Our data indicated that CFTR function could also regulate cell proliferation. Similarly, CFTR inhibition was shown to reduce kidney epithelial cell line (MDCK) cell proliferation [44]. However, higher cell proliferation was observed in regenerating CF epithelia in the xenograft model [18] and in CFTR null mice [45]. On the contrary, wt-CFTR overexpression in CFTR-/- mice increased lung secretory cell proliferation [46]. From data reported in the literature, it is thus not clear how CFTR dysfunction would impact cell proliferation. Moreover, several other parameters, including growth factors and inflammatory products, could also modulate cell proliferation and migration, and wound healing [47].

\section{Improvement of wound healing after CFTR rescue}

Our results showed, for the first time, that the CFTR corrector VRT-325 accelerated the wound closure in CFBE- $\Delta$ F508 monolayers, similarly to transduction with wt-CFTR in CF cell lines. Interestingly, the wound healing of primary human 
bronchial cell monolayers was also strongly improved (by up to 1.8 -fold) by VRT-325, showing its beneficial effect even in specimens from late-stage CF patients. Although nonspecific effects of VRT-325 cannot be excluded, recent data suggested that VRT-325 may directly bind to $\Delta$ F508-CFTR [48]. Moreover, our results provide considerable evidence that CFTR controls the wound-healing process, indicating that improved wound closure after VRT-325 treatment may be related to CFTR upregulation.

In summary, our results, as well as recent data in the literature [19], provide strong proof that CFTR function is critical for airway epithelial wound healing in vitro. A basic CFTR defect could thus be responsible, at least in part, for the delayed wound closure in CF airway monolayers. Interestingly, our findings also indicated that CFTR correction significantly accelerates CF airway wound healing, suggesting that CFTR rescue could provide a new therapeutic approach to improve the early repair processes necessary to CF airways regeneration.

\section{SUPPORT STATEMENT}

This study was funded by Cystic Fibrosis Canada (grant to E. Brochiero and studentship to N.T.N Trinh), the Association Vaincre la Mucoviscidose (grant to C. Coraux), the programme d'échange internationaux, FRSQ-INSERM (E. Brochiero and C. Coraux), CRCHUM and Université de Montréal (scholarship to E. Brochiero and studentship to $\mathrm{O}$. Bardou) and the training programme of the Respiratory Health Network and the CIHR (studentship to E. Maillé).

\section{STATEMENT OF INTEREST}

None declared.

\section{ACKNOWLEDGEMENTS}

We thank R.J. Bridges (Dept of Physiology and Biophysics, Rosalind Franklin University, North Chicago, IL, USA) and Cystic Fibrosis Foundation Therapeutics Inc. (CFFT) for providing GlyH101 and VRT325, as well as J. Riordan and CFFT for CFTR antibodies. We also thank the laboratories of Y. Berthiaume (CRCHUM, Montreal, QC, Canada) and H. Hanrahan (McGill, Montreal) for help with the primary bronchial cells. Finally, we acknowledge the editorial work of O. Da Silva and A. Hollman on this manuscript and logistical assistance from the Research Support Office, CRCHUM.

\section{REFERENCES}

1 Donaldson SH, Boucher RC. Update on pathogenesis of cystic fibrosis lung disease. Curr Opin Pulm Med 2003; 9: 486-491.

2 Courtney JM, Ennis M, Elborn JS. Cytokines and inflammatory mediators in cystic fibrosis. J Cyst Fibros 2004; 3: 223-231.

3 Shute J, Marshall L, Bodey K, et al. Growth factors in cystic fibrosis - when more is not enough. Paediatr Respir Rev 2003; 4: 120-127.

4 Hubeau C, Lorenzato M, Couetil JP, et al. Quantitative analysis of inflammatory cells infiltrating the cystic fibrosis airway mucosa. Clin Exp Immunol 2001; 124: 69-76.

5 Dovey M, Wisseman CL, Roggli VL, et al. Ultrastructural morphology of the lung in cystic fibrosis. I Submicrosc Cytol Pathol 1989; 21: 521-534.

6 Carson JL, Collier AM, Gambling TM, et al. Ultrastructure of airway epithelial cell membranes among patients with cystic fibrosis. Hum Pathol 1990; 21: 640-647.

7 Bedrossian CW, Greenberg SD, Singer DB, et al. The lung in cystic fibrosis. A quantitative study including prevalence of pathologic findings among different age groups. Hum Pathol 1976; 7: 195-204.
8 de Bentzmann S, Roger P, Puchelle E. Pseudomonas aeruginosa adherence to remodelling respiratory epithelium. Eur Respir J 1996; 9: 2145-2150.

9 de Bentzmann S, Plotkowski C, Puchelle E. Receptors in the Pseudomonas aeruginosa adherence to injured and repairing airway epithelium. Am J Respir Crit Care Med 1996; 154: S155-S162.

10 Tsang KW, Shum DK, Chan S, et al. Pseudomonas aeruginosa adherence to human basement membrane collagen in vitro. Eur Respir J 2003; 21: 932-938.

11 Roger P, Puchelle E, Bajolet-Laudinat $\mathrm{O}$, et al. Fibronectin and $\alpha 5 \beta 1$ integrin mediate binding of Pseudomonas aeruginosa to repairing airway epithelium. Eur Respir J 1999; 13: 1301-1309.

12 Sacco O, Silvestri M, Sabatini F, et al. Epithelial cells and fibroblasts: structural repair and remodelling in the airways. Paediatr Respir Rev 2004; 5: Suppl. A, S35-S40.

13 Boxall C, Holgate ST, Davies DE. The contribution of transforming growth factor- $\beta$ and epidermal growth factor signalling to airway remodelling in chronic asthma. Eur Respir J 2006; 27: 208-229.

14 Ingram JL, Bonner JC. EGF and PDGF receptor tyrosine kinases as therapeutic targets for chronic lung diseases. Curr Mol Med 2006; 6: 409-421.

15 Puddicombe SM, Polosa R, Richter A, et al. Involvement of the epidermal growth factor receptor in epithelial repair in asthma. FASEB J 2000; 14: 1362-1374.

16 Trinh NT, Prive A, Kheir L, et al. Involvement of KATP and KvLQT1 $\mathrm{K}^{+}$channels in EGF-stimulated alveolar epithelial cell repair processes. Am J Physiol Lung Cell Mol Physiol 2007; 293: L870-L882.

17 Trinh NT, Prive A, Maille E, et al. EGF and $\mathrm{K}^{+}$channel activity control normal and cystic fibrosis bronchial epithelia repair. Am J Physiol Lung Cell Mol Physiol 2008; 295: L866-L880.

18 Hajj R, Lesimple P, Nawrocki-Raby B, et al. Human airway surface epithelial regeneration is delayed and abnormal in cystic fibrosis. J Pathol 2007; 211: 340-350.

19 Schiller KR, Maniak PJ, O'Grady SM. Cystic fibrosis transmembrane conductance regulator is involved in airway epithelial wound repair. Am J Physiol Cell Physiol 2010; 299: C912-C921.

20 Zabner J, Karp P, Seiler M, et al. Development of cystic fibrosis and noncystic fibrosis airway cell lines. Am J Physiol Lung Cell Mol Physiol 2003; 284: L844-L854.

21 Bebok Z, Collawn JF, Wakefield J, et al. Failure of cAMP agonists to activate rescued deltaF508 CFTR in CFBE41o- airway epithelial monolayers. J Physiol 2005; 569: 601-615.

22 Maille E, Trinh NT, Prive A, et al. Regulation of normal and cystic fibrosis airway epithelial repair processes by TNF- $\alpha$ after injury. Am J Physiol Lung Cell Mol Physiol 2011; 301: L945-L955.

23 Aarbiou J, Verhoosel RM, van Wetering S, et al. Neutrophil defensins enhance lung epithelial wound closure and mucin gene expression in vitro. Am J Respir Cell Mol Biol 2004; 30: 193-201.

24 Geiser T, Jarreau PH, Atabai K, et al. Interleukin-1 $\beta$ augments in vitro alveolar epithelial repair. Am J Physiol Lung Cell Mol Physiol 2000; 279: L1184-L1190.

25 Pedemonte N, Lukacs GL, Du K, et al. Small-molecule correctors of defective DeltaF508-CFTR cellular processing identified by highthroughput screening. J Clin Invest 2005; 115: 2564-2571.

26 Rowe SM, Pyle LC, Jurkevante A, et al. $\triangle$ F508 CFTR processing correction and activity in polarized airway and non-airway cell monolayers. Pulm Pharmacol Ther 2010; 23: 268-278.

27 Van Goor F, Straley KS, Cao D, et al. Rescue of $\Delta$ F508-CFTR trafficking and gating in human cystic fibrosis airway primary cultures by small molecules. Am J Physiol Lung Cell Mol Physiol 2006; 290: L1117-L1130.

28 Wang Y, Loo TW, Bartlett MC, et al. Additive effect of multiple pharmacological chaperones on maturation of CFTR processing mutants. Biochem J 2007; 406: 257-263.

29 Brownlee KG. Small airways disease in cystic fibrosis. Eur Respir Mon 2006; 35: 21-37. 
30 Simel DL, Mastin JP, Pratt PC, et al. Scanning electron microscopic study of the airways in normal children and in patients with cystic fibrosis and other lung diseases. Pediatr Pathol 1984; 2: $47-64$.

31 Sobonya RE, Taussig LM. Quantitative aspects of lung pathology in cystic fibrosis. Am Rev Respir Dis 1986; 134: 290-295.

32 Knipping S, Holzhausen HJ, Riederer A, et al. Cystic fibrosis: ultrastructural changes of nasal mucosa. Eur Arch Otorhinolaryngol 2007; 264: 1413-1418.

33 Hollande E, Cantet S, Ratovo G, et al. Growth of putative progenitors of type II pneumocytes in culture of human cystic fibrosis alveoli. Biol Cell 2004; 96: 429-441.

34 Piorunek T, Marszalek A, Biczysko W, et al. Correlation between the stage of cystic fibrosis and the level of morphological changes in adult patients. J Physiol Pharmacol 2008; 59: Suppl. 6, 565-72.

35 Oikonomou A, Manavis J, Karagianni P, et al. Loss of FEV1 in cystic fibrosis: correlation with HRCT features. Eur Radiol 2002; 12: 2229-2235.

36 Hardie WD, Bejarano PA, Miller MA, et al. Immunolocalization of transforming growth factor $\alpha$ and epidermal growth factor receptor in lungs of patients with cystic fibrosis. Pediatr Dev Pathol 1999; 2: 415-423.

37 Schwab A, Nechyporuk-Zloy V, Fabian A, et al. Cells move when ions and water flow. Pflugers Arch 2007; 453: 421-432.

38 Kirk KL. CFTR channels and wound healing. Focus on "Cystic fibrosis transmembrane conductance regulator is involved in airway epithelial wound repair". Am J Physiol Cell Physiol 2010; 299: C888-C890.
39 Cheng G, Kim MJ, Jia G, et al. Involvement of chloride channels in IGF-I-induced proliferation of porcine arterial smooth muscle cells. Cardiovasc Res 2007; 73: 198-207.

40 Mao J, Chen L, Xu B, et al. Suppression of ClC-3 channel expression reduces migration of nasopharyngeal carcinoma cells. Biochem Pharmacol 2008; 75: 1706-1716.

41 Mao J, Chen L, Xu B, et al. Volume-activated chloride channels contribute to cell-cycle-dependent regulation of HeLa cell migration. Biochem Pharmacol 2009; 77: 159-168.

42 Zierler S, Frei E, Grissmer S, et al. Chloride influx provokes lamellipodium formation in microglial cells. Cell Physiol Biochem 2008; 21: 55-62.

43 Sun $\mathrm{YH}$, Reid B, Fontaine JH, et al. Airway epithelial wounds in rhesus monkey generate ionic currents that guide cell migration to promote healing. J Appl Physiol 2011; 111: 1031-1041.

44 Li H, Findlay IA, Sheppard DN. The relationship between cell proliferation, $\mathrm{Cl}-$ secretion, and renal cyst growth: a study using CFTR inhibitors. Kidney Int 2004; 66: 1926-1938.

45 Gallagher AM, Gottlieb RA. Proliferation, not apoptosis, alters epithelial cell migration in small intestine of CFTR null mice. Am J Physiol Gastrointest Liver Physiol 2001; 281: G681-G687.

46 Larson JE, Delcarpio JB, Farberman MM, et al. CFTR modulates lung secretory cell proliferation and differentiation. Am J Physiol Lung Cell Mol Physiol 2000; 279: L333-L341.

47 Crosby LM, Waters CM. Epithelial repair mechanisms in the lung. Am J Physiol Lung Cell Mol Physiol 2010; 298: L715-L731.

48 Kim CP, Wellhauser L, Huan LJ, et al. A chemical corrector modifies the channel function of F508del-CFTR. Mol Pharmacol 2010; 78: 411-418. 